\title{
Resistance to extinction as a function of the width of a tube alley'
}

Rats were given acquisition and extinction trials in Plexiglas tube alleys of varying diameters. One group was given training in a narrow alley while a second received training in a wide alley. No differences were found between the groups in resistance to extinction. The results were interpreted as being inconsistent with interference theories of extinction.

According to contiguity theory extinction is due to counter-conditioning, or to the conditioning of competing responses. Martindale (1955) used alleys made of glass tubing of varying diameters to manipulate the number of competing responses in the rat's running behavior. All Ss received 15 continuously reinforced trials, at one trial per day, in a $72 \mathrm{~mm}$ diameter alley. They then were assigned to three groups which received 25 extinction trials, at one trial per day, in tubes with diameters of 62,72 , and $82 \mathrm{~mm}$, respectively. The 72 $\mathrm{mm}$ group showed virtually no extinction while the 82 $\mathrm{mm}$ group exhibited a normal extinction curve. Surprisingly, the $62 \mathrm{~mm}$ group extinguished most rapidly. This may be due to a high probability of competing responses at the starting platform resulting in a large generalization decrement for the initial running response of the $62 \mathrm{~mm}$ Ss. To eliminate differential generalization decrements acquisition and extinction trials should be given in the same alley or in different alleys with each containing a narrow initial segment and a narrow startbox.

The present study used two clear Plexiglas tube alleys of different diameters and identical narrow startboxes and narrow initial segments. In the present study the Ss were given acquisition and extinction in the same alley. The use of narrow initial segments and narrow startboxes in both alleys was adopted to allow for change in alleys from acquisition to extinction in future studies. The present study represents a replication of Martindale with more acquisition and extinction trials, shorter trial spacing and some apparatus modifications.

\section{METHOD}

\section{Subjects}

Thirty-six female albino rats, $120-150$ days old at the start of the experiment were purchased from Albino Farms, Red Bank, New Jersey.

\section{Apparafus}

A narrow and a wide clear Plexiglas tube alley were used. The alleys had identical clear plexiglas startboxes which were $3 \times 3 \times 10$ in. and identical initial tube segments which were 12 in. long and $56 \mathrm{~mm}$ in diameter. The initial tube segment joined a 78-in. tube which was $56 \mathrm{~mm}$ and $81 \mathrm{~mm}$ for the narrow and wide alleys, respectively. The last 18-in. of each tube served as a goalbox. The goalbox section of the tube was cut and hinge mounted so that the top one-third of each goalbox could be raised. Both alleys were enclosed in standard wood alleys painted flat gray throughout. The wood alleys were $5 \mathrm{in}$. high, $90 \mathrm{in}$. long, and 4 and 6 in. wide for the narrow and wide tubes, respectively. Illumination was provided by two 100-w bulbs approximately $6 \mathrm{ft}$. above the apparatus.

Startboxes and goalboxes were separated from the alleys by aluminum guillotine doors. Another aluminum guillotine door separated the drinking tube from the goalbox. Water reinforcement was provided through a brass drinking tube.

Holes were cut in the side walls of the wood alleys to permit the passage of light beams. The holes were placed 6 in. past the startbox door and 9 in. past the goalbox door to record starting time and running time, respectively. Two Standard Electric .01-sec. timers started when the startbox door was opened and stopped by photocell circuits. An air conditioner was run continuously to provide a uniform masking noise. Procedure

Two weeks before the beginning of the experiment Ss were placed on a $20 \mathrm{hr}$. water deprivation schedule and given access to water for 1-1/2 to $2 \mathrm{hr}$. Each $\mathrm{S}$ received $1 \mathrm{~min}$. of gentling each day for 2 weeks.

The Ss were then assigned randomly to three groups. One group was given acquisition and extinction in the wide alley (Group $W$ ), while a second received all of its trials in the narrow alley (Group N). A third group was given nonreinforced trials in the narrow alley (Group NC) to control for aversive effects that may arise in the narrow tube.

Groups $\mathrm{W}$ and $\mathrm{N}$ were given 82 acquisition and 61 extinction trials, while Group NC received 143 nonreinforced trials. Trials 1-10 were given at one trial per day. Thereafter, Ss were given two trials per day with an intertrial interval of approximately $45 \mathrm{~min}$. It was planned to run the Ss until the group curves appeared to level off and then run an additional 12 trials and perform statistical analysis on these data regardless of the nature of the data collected. As a result Ss were given 82 acquisition trials. The next day all Ss were given one noureinforced trial, which was followed by 60 extinction trials. The Ss were run to extinction asymptote or until they failed to leave the startbox after $5 \mathrm{~min}$. had elapsed for two consecutive trials. None of the Ss reached the extinction criteria. 


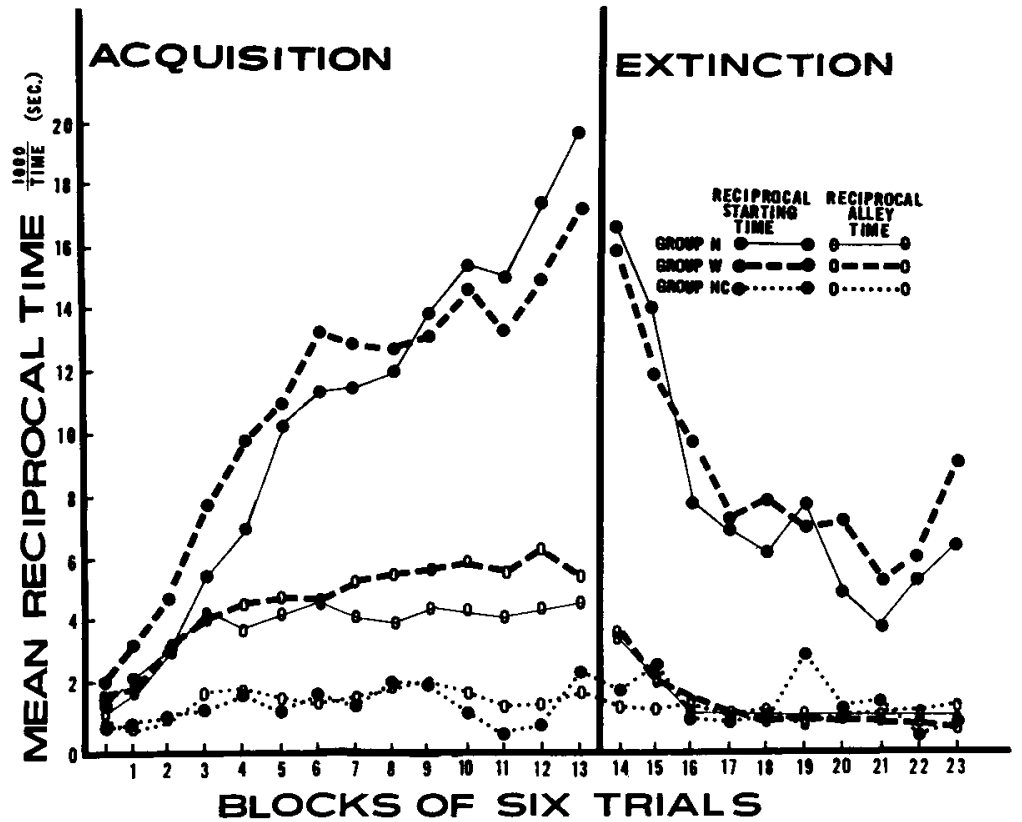

Fig. 1. Mean reciprocal time as a function of trials in blocks of six for acquisition and extinction. (The first data point represents the mean of the first four training trials.
The discard criterion adopted for acquisition was failure to leave the startbox within $20 \mathrm{~min}$. on two consecutive trials. Four Ss died during the course of the experiment and five met the discard criterion on the early training trials, leaving 11 Ss in Group $N$ and in Group W and five in Group NC.

On each trial $S$ was placed in the startbox and after a 2 to 3 sec. delay the startbox door was raised. The startbox and goalbox doors were lowered after $S$ had passed under them to prevent retracing. After $S$ was removed from the goalbox, it was returned to its home cage. Except for trials 1-4, after $S$ had penetrated to a distance of $1 \mathrm{in}$. from the end wall of the goalbox, the door in front of the drinking tube was raised and $S$ was permitted $30 \mathrm{sec}$. of drinking as reinforcement. On trials 1-4 the guillotine door was raised before $\mathrm{S}$ was placed in the startbox. On trial 1, the drinking tube projected through the slot into the goalbox, and on trials 2, 3, and 4 the tube was gradually withdrawn so that on trial 4 the tip of the drinking tube was flush against the slot in the end wall. The tube remained in this position for the rest of the experiment. On all nonreinforced trials the guillotine door in front of the drinking tube was left in the down position and the Ss were detained in the goalbox for $30 \mathrm{sec}$. Approximately 15-30 min. after the last $\mathrm{S}$ was run the $\mathrm{Ss}$ were given access to water in their home cages for $90 \mathrm{~min}$. RESULTS AND DISCUSSION

\section{Acquisition}

Mean reciprocal starting time (1000/starting time) and mean reciprocal running time (1000/running time) are presented as a function of trials in blocks of six in Fig. 1. Statistical analysis of the last 12 trials indicated that there were no significant differences between Groups $N$ and $W$ on either measure $(t<1$, $\mathrm{df}=20$ for both measures). No statistical comparison was made between these two groups and Group NC as inspection of the group curves reveals that Group NC was obviously running slower on both measures. Extinction

Parallel analyses of covariance were performed for both measures for extinction trials $1-30,31-60$, and 1-60 with the mean for the last 12 acquisition trials taken as the control variable. No significant differences were found ( $\mathrm{F} \leq 1.31, \mathrm{df}=1 / 19$ for all comparisons).

A fourfold increase in mean reciprocal starting time and a threefold increase in mean reciprocal running time was found for Group NC, although both measures subsequently declined.

After 60 extinction trials Groups $\mathrm{N}$ and $\mathrm{W}$ were still running faster than Group NC for the starting time measure. For the running time measure Groups $\mathrm{N}$ and $\mathrm{W}$ appeared to have leveled off at approximately the same level as that of Group NC. No significant differences were found between Groups $\mathrm{N}$ and $\mathrm{W}$. combined and Group NC for extinction trials 1-30, 31-60, and 1-60 ( $t \leq 1.75$, df $=25$ for all comparisons).

Thus, no effect was found on resistance to extinction due to width of the tube alley.

The failure to replicate Martindale's results poses a problem for interference theories of extinction.

\section{Reference}

Martindale, R. L. Extinction of a running response as a function of the size of a tube runway. Unpublished doctoral dissertation, Michigan State University, 1955.

\section{Note}

1. The writer is very much indebted to $\mathbf{S}$. Weinstock under whose direction the research was conducted. 